\title{
Prevalence, Awareness and Factors Associated with Glaucoma in a Rural Community of Ekiti State, South West Nigeria
}

\author{
Rasaq Kayode Adewoye1,2, Tayo Ibrahim ${ }^{2,3}$, Shuaib Kayode Aremu ${ }^{2,4^{*}}$, Taiye Adeyanju Alao5, \\ Makinde Adebayo Adeniyi ${ }^{5}$, Adewumi Bakare ${ }^{2,6}$ \\ ${ }^{1}$ Community Medicine Department, Federal Teaching Hospital, Ido-Ekiti, Nigeria \\ ${ }^{2}$ Afe Babalola University, Ado-Ekiti, Nigeria \\ ${ }^{3}$ Ophthalmology Department, Federal Teaching Hospital, Ido-Ekiti, Nigeria \\ ${ }^{4}$ ENT Department, Federal Teaching Hospital, Ido-Ekiti, Nigeria \\ ${ }^{5}$ Community Medicine Department, Federal Teaching Hospital, Ido-Ekiti, Nigeria \\ ${ }^{6}$ Obstetrics and Gynecology Department, Federal Teaching Hospital, Ido-Ekiti, Nigeria \\ Email: *shuaib. aremu@gmail.com
}

How to cite this paper: Adewoye, R.K. Ibrahim, T., Aremu, S.K., Alao, T.A., Adeniyi, M.A. and Bakare, A. (2019) Prevalence, Awareness and Factors Associated with Glaucoma in a Rural Community of Ekiti State, South West Nigeria. Open Journal of Ophthalmology, 9, 18-27.

https://doi.org/10.4236/ojoph.2019.91003

Received: December 7, 2018

Accepted: January 15, 2019

Published: January 18, 2019

Copyright $\odot 2019$ by author(s) and Scientific Research Publishing Inc. This work is licensed under the Creative Commons Attribution International License (CC BY 4.0).

http://creativecommons.org/licenses/by/4.0/

(c) (i) Open Access

\begin{abstract}
Background: Glaucoma, a group of diseases that have optic neuropathy as a common end point, is the leading cause of irreversible blindness worldwide, accounting for 4.5 million blindness, which is about $12 \%$ of global blindness. This study aimed to assess the prevalence, awareness and risk factors associated with glaucoma in a rural community of Ekiti State. Methodology: This was a cross-sectional study conducted during a health outreach. All adults present during the outreach were enrolled into the study and screened for glaucoma and a semi-structured self-administered questionnaire was used for data collection. The validity of the questionnaire was tested at Ijero-Ekiti community before being used for this research. Data obtained was analysed using SPSS version 20 and p-value was predetermined at $\leq 0.05$. Results: Majority of respondents were aged 60 years and above with a mean age of 55 \pm 11.7 . Majority (73\%) were females and $41 \%$ had secondary education. Prevalence of glaucoma was $10.7 \%$; $36 \%$ of respondents had heard about glaucoma; and $43.2 \%$ of those that had heard were not aware that it can lead to blindness. Increasing age, level of education, procurement of glasses from friends/relatives/roadside, using eyes drop not prescribed, history of previous eyes injury and family history of glaucoma were factors identified as having significant relationship with glaucoma. Conclusion: Glaucoma is prevalent in the community (10.7\%). However, level of awareness about the disease (36\%) was low. Factors, such as age, level of education, procurement of glasses from quacks, use of eye drops not prescribed, previous injury to the eyes and family
\end{abstract}


history of glaucoma, were shown to have significant relationship with glaucoma. There is need to increase community awareness on glaucoma as a major cause of blindness and the risk factors associated with it. Community screening for people above 40 years for glaucoma is also recommended.

\section{Keywords}

Glaucoma, Blindness, Neuropathy

\section{Introduction}

Worldwide, 285 million people are estimated to be visually impaired with 39 million people estimated to be blind [1]. Glaucoma is the second leading cause of blindness globally after cataract. It is the leading cause of irreversible blindness, accounting for 4.5 million blindness, which is about $12 \%$ of global blindness [2].

Glaucoma is a group of diseases that have optic neuropathy as a common end point. The structural and functional deficit occurs as a result of increasing intra ocular pressure leading to damage of the optic nerve at the point where it entered the eye [2] [3]. The two must common types are the Primary Open Angle Glaucoma (POAG) which is characterized by progressive narrowing of the neuroretinal rim with an associated increase in the cupping of the optic disc and Angle Closure glaucoma which is less common and occurs when the drains of the eyes become blocked, the intro-occular pressure rises and the iris is pushed forward, closing off the drainage [4] [5] [6]. The incidence of POAG rises with age and is more frequent in people of African Origin [2]. Glaucoma affects 1 in 20 people aged fifty years and younger, and 1 in ten people over the age of eighty years [7]. Global prevalence of glaucoma for population 40 - 80 years from prevalence surveys as at 2013 was $3.57 \%$ with possible 64.3 million people and projections of 76 million and 111.8 million people with glaucoma by 2020 and 2040 respectively [8]. Glaucoma affects about $4 \%$ of African Adults aged 40 years and above and accounts for about 15\% of blindness [5] [9] [10] [11]. Nigerian blindness survey in 2009 reported blindness prevalence of $4.2 \%$, out of which $16.7 \%$ was due to glaucoma, giving glaucoma prevalence of $5.02 \%$ and glaucoma specific blindness prevalence of 0.7\% [12] [13] [14].

The condition is reversible or if detected early and appropriated treatment instituted [7]. One of the methods for timely detection and treatment is by having regular eye screening during adulthood made possible with awareness of glaucoma [14]. Awareness about glaucoma, glaucoma risk factors and prevention has been shown to reduce the chance of functional disability and vision loss [15]. Studies conducted in Osun and Ebonyi States of Nigeria showed that $84.2 \%$ and $78 \%$ respectively of respondents had never heard of glaucoma [15] [16].

Several factors relating to the development of glaucoma have been identified. These include increasing age, male gender, race/ethnicity, illiteracy, level of in- 
trao-ccular pressure, type II diabetes Mellitus, previous history of trauma to the eye, myopia, systemic hypertension, and family history of glaucoma [4] [17].

Few community studies have been conducted on glaucoma in Nigeria, particularly in Ekiti State. This study therefore, aimed to assess the prevalence, awareness and risk factors associated with glaucoma.

\section{Methodology}

The Study was carried out September 2018, in Ikole Ekiti in Ikole Local Government Area of Ekiti State.

Health outreach was organized in Ikole-ekiti by the Department of Opthamology, Federal Teaching Hospital Ido-ekiti in conjunction with the department of Community Medicine of the same institution. Advocacy visit was paid to the traditional head of the community before the commencement of outreach programme. The study design was a descriptive cross sectional study. All Adults who presented for the outreach were enrolled into the study and screened for glaucoma. A total of 122 adults were screened. A semi-structured self-administered questionnaire (Appendix I) was used to elicit sociodemographic characteristics, Awareness of glaucoma, and risk factors of glaucoma. Data were analysed using SPSS version 20. Tables were generated and $\mathrm{P}$ value was pre-determined at $<$ 0.05. Ethical clearance was obtained from the ethics and research unit of Federal Teaching Hospital Ido-ekiti.

Diagnostic criteria for glaucoma

Optic Disc Status-CDR (Cup-Disc Ratio). Evidence of Optic nerve damage with $\mathrm{CDR} \geq 0.6$ and/ or CDR difference of both eye $\geq 0.2$.

\section{Results}

One hundred and twenty two (122) questionnaires were properly filled, returned and analyzed. Majority, 46 (37.7\%) of the respondents were 60 years and above, $44(36.1 \%)$ of the respondents were between 51 - 60 years of age while, 32 (26.2\%) were less than 50 years (Table 1 ). Mean age of respondents was $55.2 \pm$ 11.7. Majority of the respondents were females, $89(73 \%)$, most of the respondents had secondary education, 50 (41\%), 25 (20.5\%), had tertiary education while $20,(18.0 \%)$ had no education.

The prevalence of glaucoma in this study was 13 (10.7\%) (Figure 1). Only, 44 (36.1\%) of the respondents had ever heard about glaucoma while 78 (63.9\%) had never heard about glaucoma (Table 2). Out of the respondents that had ever heard about glaucoma, 19 (43.2\%) knew that glaucoma can cause blindness while $25(56.8 \%)$ did not know that glaucoma can cause blindness.

Test of relationship between presence of glaucoma and sociodemographic characteristics of respondents showed significant relationship between glaucoma and increasing age $(\mathrm{p}=0.040)$. There was also significant relationship between presence of glaucoma and level of education with p-value of 0.033 (Table 3).

There was statistically significant relationship between glaucoma and Sources of glasses $(p=0.014)$. Respondents who got their glasses from friend/relative 
Table 1. Socio-demographic characteristics of respondents.

\begin{tabular}{ccc}
\hline Variable & $\begin{array}{c}\text { Frequency } \\
(\mathrm{N}=122)\end{array}$ & $\begin{array}{c}\text { Percentage } \\
(\%)\end{array}$ \\
\hline Age group (in years) & 32 & 26.2 \\
$\leq 50$ & 44 & 36.1 \\
$51-60$ & 46 & 37.7 \\
$>60$ & $55.2 \pm 11.7$ & \\
Mean \pm SD & $23-72$ & \\
Range & & 27.0 \\
Sex & 33 & 73.0 \\
\hline Male & 89 & \\
Female & & 18.0 \\
\hline Level of Education & 22 & 20.5 \\
None & 25 & 41.0 \\
Primary & 50 & 20.5 \\
\hline Secondary & 25 & \\
Tertiary & & \\
\hline
\end{tabular}

Table 2. Awareness of respondents about glaucoma.

\begin{tabular}{ccc}
\hline Variable & $\begin{array}{c}\text { Frequency } \\
(\mathbf{N}=122)\end{array}$ & $\begin{array}{c}\text { Percentage } \\
\text { (\%) }\end{array}$ \\
\hline Ever heard of glaucoma & & \\
Yes & 44 & 36.1 \\
No & 78 & 63.9 \\
\hline Know that glaucoma can cause blindness $(\mathrm{n}=\mathbf{4 4})$ & & \\
\hline Yes & 19 & 43.3 \\
No & 25 & 56.8 \\
\hline
\end{tabular}

Table 3. Relationships between socio-demographic characteristics and glaucoma prevalence.

\begin{tabular}{ccccc}
\hline Variable & \multicolumn{2}{c}{ Glaucoma } & $\chi^{2}$ & p \\
\hline Yes & $\begin{array}{c}\text { No } \\
\mathbf{n}(\%)\end{array}$ & & \\
\hline Age group (in years) & & & & \\
\hline$\leq 50$ & $1(3.1)$ & $31(96.9)$ & 6.422 & 0.040 \\
$51-60$ & $3(6.8)$ & $41(93.2)$ & & \\
$>60$ & $9(19.6)$ & $37(80.4)$ & & 0.502 \\
\hline Sex & & & & \\
\hline Male & $2(6.1)$ & $31(93.9)$ & $0.451^{*}$ & \\
Female & $11(12.4)$ & $78(87.6)$ & & \\
\hline Level of Education & & & & \\
\hline None & $6(27.3)$ & $16(72.7)$ & 9.730 & \\
Primary & $3(12.0)$ & $22(88.0)$ & & \\
Secondary & $3(6.0)$ & $47(94.0)$ & & \\
Tertiary & $1(4.0)$ & $24(96.0)$ & & \\
\hline
\end{tabular}




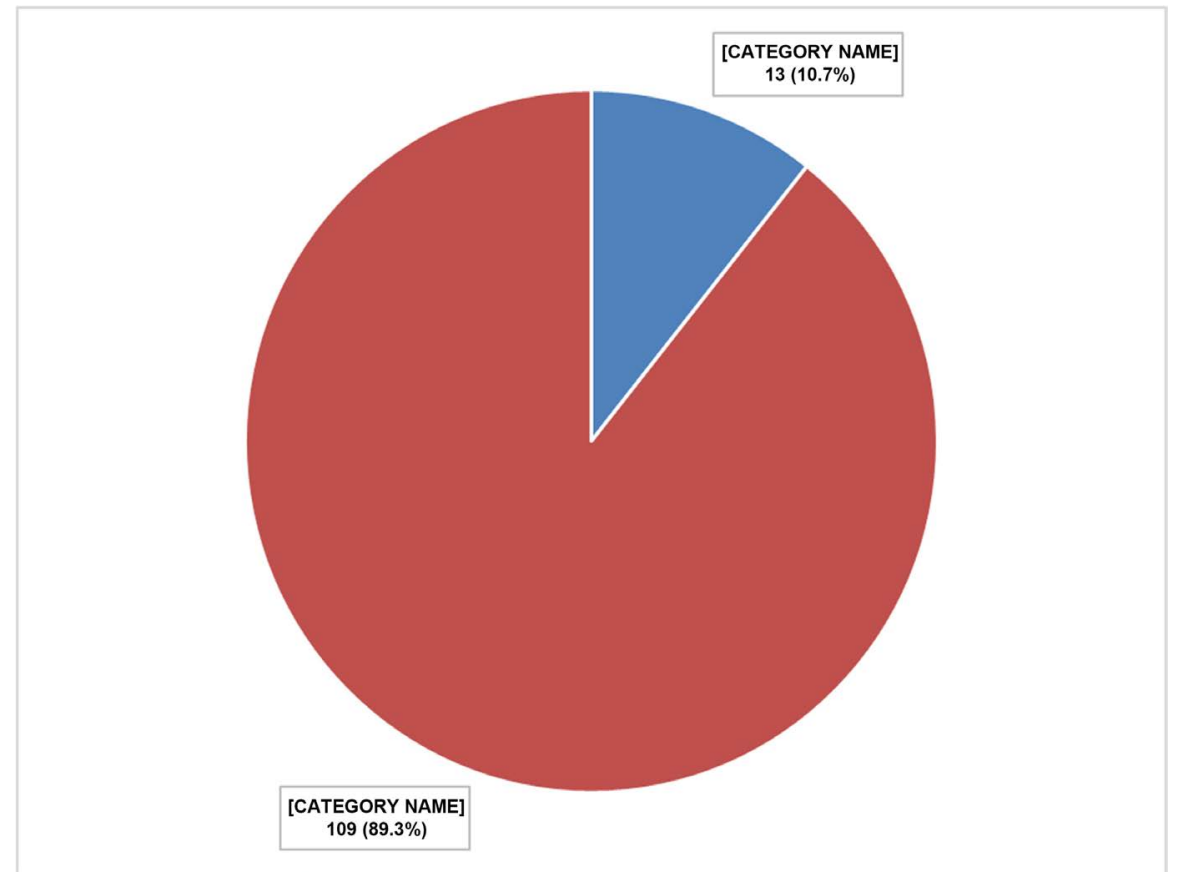

Figure 1. Prevalence of glaucoma among respondents.

and from the roadside were about 5.76 and 7.20 times respectively more likely to have glaucoma than those who got theirs from the eye clinic. Using of eye drops not prescribed had statistical relationship with presence of glaucoma $(\mathrm{p}=$ 0.0310) (Table 4). Those who had ever used eye drops not prescribed had 5.81 times more likelihood of having glaucoma than respondents who had not. Also, history of previous eye injury had relationship with glaucoma $(\mathrm{p}=0.05)$. Respondents who had ever had an eye injury were about 6.24 times more likely to develop glaucoma than those who had not. Finally, family history of eye problem and presence of glaucoma had statistically significant relationship $(\mathrm{p}=0.014)$. Respondents who had a family history of an eye problem were 4.89 times more likely to develop glaucoma.

\section{Discussion}

The prevalence of glaucoma in this study was $10.7 \%$. This result was higher than the national prevalence of 5.02\% [12] [13] [14]. This difference with the National value may be due to the fact that study was conducted only in a rural community of Southwestern Nigeria and the fact that rural dwellers have poor access to health care, including eye care. Research has also shown that ethnicity with the Igbo and Yoruba tribes of being a risk factor for glaucoma [4]. This may account for the high prevalence in our study. The result was however similar to a rural and urban study conducted in Ilorin, Nigeria with a rural prevalence of $12.5 \%$ and urban prevalence of $8.2 \%$ [18]. The high prevalence could also be as a result of more people living to old age which predisposed elderly people to degenerative changes in the body and chronic diseases like glaucoma [19]. 
Table 4. Relationships between some risk factors glaucoma prevalence.

\begin{tabular}{|c|c|c|c|c|}
\hline \multirow[t]{3}{*}{ Variables } & \multicolumn{2}{|c|}{ Glaucoma } & & \multirow[t]{3}{*}{$\mathrm{P}$} \\
\hline & Yes & No & & \\
\hline & $\mathrm{n}(\%)$ & $\mathrm{n}(\%)$ & & \\
\hline \multicolumn{5}{|l|}{ Wear glasses } \\
\hline Yes & $8(13.8)$ & $50(86.2)$ & 1.143 & 0.285 \\
\hline No & $5(7.8)$ & $59(92.2)$ & & \\
\hline \multicolumn{5}{|l|}{ Source of glasses } \\
\hline Eye clinic & $5(12.2)$ & $36(87.8)$ & 8.475 & 0.014 \\
\hline Roadside & $4(50.0)$ & $4(50.0)$ & & \\
\hline Friend/ Relative & $4(44.4)$ & $5(55.6)$ & & \\
\hline \multicolumn{5}{|c|}{ Ever used eye drops not prescribed } \\
\hline Yes & $11(17.2)$ & $53(828)$ & 4.676 & 0.031 \\
\hline No & $2(3.4)$ & $56(96.6)$ & & \\
\hline \multicolumn{5}{|c|}{ Ever been treated at an eye clinic } \\
\hline Yes & $3(7.1)$ & $39(92.9)$ & 0.362 & 0.547 \\
\hline No & $10(12.5)$ & $70(87.5)$ & & \\
\hline \multicolumn{5}{|l|}{ Ever measured IOP } \\
\hline Yes & $1(5.6)$ & $17(94.4)$ & 0.12 & 0.729 \\
\hline No & $12(11.5)$ & $92(88.5)$ & & \\
\hline \multicolumn{5}{|c|}{ Ever had an eye injury in the past } \\
\hline Yes & $3(37.5)$ & $5(62.5)$ & 3.814 & 0.05 \\
\hline No & $10(8.8)$ & $104(91.2)$ & & \\
\hline \multicolumn{5}{|c|}{ Family history of eye problem } \\
\hline Yes & $7(25.0)$ & $21(75.0)$ & 6.02 & 0.014 \\
\hline No & $6(6.4)$ & $88(93.6)$ & & \\
\hline
\end{tabular}

Few (36.1\%) of the respondents in this study had never heard about glaucoma and majority (56.8\%) of those that had heard about glaucoma, did not know that the condition can lead to blindness. This low level of awareness was also demonstrated with awareness of $32 \%$ [20], 15.8\% [15], and 21.1\% [16] obtained from studies that were conducted in southern India, Osun State and Eboyin State, Nigeria, respectively. The India study is also similar to finding in this study with $55 \%$ of respondents who had ever heard of glaucoma not knowing that it can cause blindness [20]. However this study differs from a community study in Canada with glaucoma awareness of $73 \%$ [21]. This difference could be accounted for by the high level of development, high literacy rate and good access to health care in developed countries like Canada. Also, this study result predictably differs from that of a study conducted among Primary care givers, whose training gave them the opportunity to know about glaucoma, in Shaga$\mathrm{mu}$, Ogun State, with awareness of $97 \%$ [22]. The low level of awareness could be because of the insidious and initial asymptomatic nature of the disease and 
poor access of the people to eye clinics with glaucoma screening facility and treatment.

This study showed a relationship between presence of glaucoma and sociodemographic characteristics of respondents. This relationship include increasing age $(\mathrm{p}=0.040)$, and level of education $(\mathrm{p}=0.033)$. Similar glaucoma studies by Durowade et al. [17] and Kyari et al. [4], also showed significant relationship with increasing age and literacy $(\mathrm{p}=0.035)$ and $(\mathrm{p}=0.001)$. The relationship with increasing age can be explained with increasing risk degenerative diseases as one ages and the exposure to risk factors over several years. People with high level of literacy are more likely to be aware about the disease and will most likely present for screening and early treatment. This study however did not show a relationship between glaucoma and gender. This is in contrast to findings of Durowade et al. and Kyari et al. when male gender were shown to be more at risk than female gender [4] [17]. This difference may be as a result of more old women living to old age as found in rural communities of Ekiti state.

Factors that were showed to have relationship with glaucoma includes procurement of glasses form friends/relatives/roadside $(\mathrm{p}=0.014)$, used eye drops not prescribed by ophthalmologists $(\mathrm{p}=10.031)$ previous eye injury $(\mathrm{p}=0.05)$ and family history of eye problem $(\mathrm{p}=0.014)$. Previous study in Ilorin [17] had shown Unemployment $(\mathrm{p}=0.000004)$, high IOP $(\mathrm{p}=0.029)$, Known hypertensive $(p=0.002)$ and prolonged use of analgesic $(p=0.004)$ as factors associated with glaucoma. A Nigerian study also showed that systemic hypertension ( $\mathrm{p}=$ $0.002)$ and Underweight $(\mathrm{p}=0.0001)$ are significantly related to glaucoma. Respondents who procure their glasses from eye-clinic will have the opportunity of undergoing comprehensive eye examination which will help in detecting those with raise intra ocular pressure and appropriate treatment would be instituted early to normalize the intra-occular pressure thereby preventing the occurrence/progression of glaucoma whereas those who procure their glasses from other means(road side/relative or friends etc.) will not have the opportunity of eye examination or screening by qualify health personnel thereby worsening their eye condition. This may be the possible explanation for higher prevalence of glaucoma among the respondents that obtained their glasses from road side or from relative or friends than those that obtained theirs from the eye-clinic. Higher prevalence of glaucoma among respondents with history of use of un-prescribed eye drops might be due to the fact that some eye drops contain corticosteroid. Repeated or long term use of corticosteroid containing eye-drop not prescribed by a qualify health personnel is an important risk factor for the occurrence of glaucoma Self-medication with eye drops which contains corticosteroids causes damage to the eyes and predisposes to glaucoma.

Previous injury to the eye could leave a permanent damage to structures of the eyes and the draining pathway of the lacrimal fluid. People with family history might however have a genetic predisposition to glaucoma.

A major limitation of the study is that it was carried out in only one community out of several communities in Ekiti State. 


\section{Conclusion}

This study has shown that glaucoma is prevalent in our population, with a prevalence of $10.7 \%$. There is, however, low level of awareness of the disease (36.1\%) and low awareness of the consequence of irreversible blindness (43.2\%). This study also showed increasing age and level of literacy are factors for development of glaucoma. Other factors include procurement of glasses from quacks, use of eye drops without prescription, previous history of eye injury and family history of eye problem as factors associated with glaucoma. It is therefore recommended that Community screening for glaucoma for people above 40 years should be encouraged to ensure early diagnosis and treatment. Also, health education about glaucoma risk factors and prevention should be provided to the people through the health-workers, mass media and social media. Any adult with a family history of glaucoma should be advised to go for regular screening for glaucoma. Use of eye drop without prescription should be discouraged among the populace. People with visual problem should be advised to always consult trained ophthalmologist.

\section{Conflicts of Interest}

The authors declare no conflicts of interest regarding the publication of this paper.

\section{References}

[1] World Health Organization. (2013) Universal Eye Health. A Global Action Plan 2014-2019. WHO. https://www.who.int/blindness/actionplan/en/

[2] World Health Organisation. (2018) Priority Eye Diseases. In WHO. Blindness and Visual Impairment Prevention. https:www.who.int/blindness/causes/priority/en/index6.html

[3] Krishnaiah, S., Kovai, V., Srinnivas, M., Shamana, B.R., Rao, G.N. and Thomas, R. (2005) Awareness of Glaucoma in the Rural Population of Southern India. Indian Journal of Ophthalmology, 53, 205-208. https://doi.org/10.4103/0301-4738.16685

[4] Kyari, F., Abdull, M.M., Wormald, R., Evans, J.R., Nolan, W., Murthy, G.V.S. and Gilbert, C.E. (2016) Risk Factors for Open Angle Glaucoma in Nigeria: Results from the National Blindness and Visual Impairment Survey. BMC Ophthalmology, 16, 18. https://doi.org/10.1186/s12886-016-0264-7

[5] Wilson, S., Oren, G. and Newman-Casey, P.A. (2018) Primary Open Angle Glaucoma. Kellog Eye Centre, University of Michigan Health System. https://www.med.umich.edu/1libr/ophthalmoligy/glaucoma/PrimaryOpenAngleGla ucoma

[6] Kellogg Eye Center, Michigan Medicine. (2019) Glaucoma. https:www.umkelloggeye.org/conditions-treatments/glaucoma

[7] World Health Organisation. (2018) Global Trends in the Magnitude of Blindness and Visual Impairment. Bulletin of the World Health Organisation. http://www.who.int/blindness/causes/trends

[8] Tham, Y.C., Li, X., Wong, T.Y., Quigley, H.A., Aung, T. and Cheng, C.Y. (2014) Global Prevalence of Glaucoma Burden through 2040: A Systematic Review and 
meta-Analysis. Ophthalmology, 121, 2081-2090.

https://doi.org/10.1016/j.ophtha.2014.05.013

[9] Cook, C. (2009) Glaucoma in Africa, Size of the Problem and Possible Solutions. Journal of Glaucoma, 18, 124-128. https://doi.org/10.1097/IJG.0b013e318189158c

[10] Ogbonnaya, C.E. (2012) Profile of Blindness and Low Vision at Ebonyi State University Teaching Hospital (EBSUTH), Abakaliki. EMJ, 11, 13-15.

[11] Rastawrous, A., Burgess, P.L., Mahdi, A.M., Kyari, F., Burton, M.U. and Kuper, H. (2014) Posterior Segment Eye Disease in Sub Saharan Africa. Review of Recent Population Based Studies. Tropical Medicine \& International Health, 19, 600-609. https://doi.org/10.1111/tmi.12276

[12] Kyari, F., Gudlavalleti, M.V., Sivsubramanian, S., Gilbert, C.E., Abdul, M.M., Entekume, G., et al. (2009) Prevalence of Blindness and Visual Impairment in Nigeria. The National Blindness and Visual Impairment Study. Investigative Ophthalmology \& Visual Science, 50, 2033-2039. https://doi.org/10.1167/iovs.08-3133

[13] Abdul, M.M., Sivasubramanian, S., Murthy, G.V., Gilbert, C., Tafida, A., Ezelum, C., et al. (2009) Causes of Blindness and Visual Impairment in Nigeria. The Nigeria National Blindness and Visual Impairment Survey. Investigative Ophthalmology \& Visual Science, 50, 4114-4120. https://doi.org/10.1167/iovs.09-3507

[14] Kyari, F., Entekume, G., Rabiu, M., Spry, P., Wormald, R. and Nolan, W. (2015) A Population-Based Survey of the Prevalence and Types of Glaucoma in Nigeria: Results from the National Blindness and Visual Impairment Survey. BMC Ophthalmology, 15, 176. https://doi.org/10.1186/s12886-015-0160-6

[15] Isawumi, M.A., Hassan, M.B., Akinwusi, P.O., Adebimpe, W.O., Asekun-Olarinmoye, E.O., Christopher, A.C. and Adewole, T.A. (2014) Awareness of and Attitude towards Glaucoma among an Adult Rural Population of Osun State, Southwest Nigeria. Middle East African Journal of Ophthalmology, 21, 165-169.

[16] Ogbonnaya, C.E., Ogbonnaya, L.U., Okoye, O. and Kizor-Akaraiwe, N. (2016) Glaucoma Awareness and Knowledge, and Attitude to Screening in a Rural Community of Ebonyi State, Nigeria. Open Journal of Ophthalmology, 6, 119-127. https://doi.org/10.4236/ojoph.2016.62017

[17] American Academy of Ophthalmologists (2015) Primary Open Angle Glaucoma. Elsevier Inc., Amsterdam, 41-110.

[18] Durowade, K.A., Salaudeen, A.G., Akande, T.M., Musa, I.O., Olokoba, L.B., Ibrahim, T., et al. (2016) Prevalence and Risk Factors of Glaucoma among Adults in Rural and Urban Communities of Ilorin West Local Government Area, North-Central Nigeria. International Journal of Clinical Medicine Research, 3, 6-12.

[19] Nation (2002) Department of Economic and Social Affairs, Population Division.

[20] Krishnaiah, S., Korai, V., Snnivas, M., Shamanna, B.R., Rao, G.N. and Thomas, R. (2005) Awareness of Glaucoma in Rural Population of Southern India.

[21] Altangerel, U., Nallamshetty, H.S., Uhler, T., Fontanarosa, J., Steinnman, W.C., Almodin, J.M., et al. (2009) Knowledge about Glaucoma and Barriers to Follow-Up Care in a Community Glaucoma Screening Program. Canadian Journal of Ophthalmology, 44, 66-69. https://doi.org/10.3129/i08-175

[22] Onabolu, O.O. and Bodunde, O.T. (2014) Awaremess and Knowledge of Glaucoma among Primary Care Givers in a Developing Country. Annals of Tropical Medicine and Public Health, 7, 5-8. https://doi.org/10.4103/1755-6783.144997 


\section{Appendix I: Questionnaire}

Your age in years

Sex, Male

Level of Education

\section{Female}

Primary secondary Graduate None

Yes

Where did you get the glasses from Road side Friend/relative Eye Clinic

Have you ever used eye drops not prescribed by doctors? Yes No

Have you ever been treated at eye clinic Yes No

Have you ever of the word "Glaucoma" Yes No

Do you know that glaucoma can cause blindness Yes No

Have you ever measured your blood pressure (BP)? Yes No

Do you know that the eyes have its own blood pressure? Yes No

Have you ever had your eye blood pressure checked? Yes No

Have you had injuries to your eye? Yes No

Does any of your relatives have eye problem? Yes No 